\title{
Knowledge, Attitudes and Practices of Caregivers of Children 0 - 23 Months in Eastern and Central Uganda
}

\author{
Jacent Kamuntu Asiimwe ${ }^{1 *}$, Joweria Nambooze1, George Wilson Ssonko², James Kakande², \\ Lilian Nyanzi ${ }^{2}$, Peter Kaddu ${ }^{3}$ \\ ${ }^{1}$ Kyambogo University, Kampala, Uganda \\ ${ }^{2}$ Nutrea Consults Ltd., Kampala, Uganda \\ ${ }^{3}$ Living Goods, Kampala, Uganda \\ Email: ^jacentasiimwe@rcsi.ie, ^jkamuntu@kyu.ac.ug
}

How to cite this paper: Asiimwe, J.K., Nambooze, J., Ssonko, G.W., Kakande, J., Nyanzi, L. and Kaddu, P. (2021) Knowledge, Attitudes and Practices of Caregivers of Children 0 - 23 Months in Eastern and Central Uganda. Food and Nutrition Sciences, 12, 494-508.

https://doi.org/10.4236/fns.2021.126038

Received: April 14, 2021

Accepted: June 8, 2021

Published: June 11, 2021

Copyright $\odot 2021$ by author(s) and Scientific Research Publishing Inc. This work is licensed under the Creative Commons Attribution International License (CC BY 4.0).

http://creativecommons.org/licenses/by/4.0/

(c) (i) Open Access

\begin{abstract}
Introduction: Appropriate feeding and consequently good nutritional status of young children largely depends on their caregivers. Aim: The current study aimed at assessing maternal/caregivers' current knowledge, attitudes, practices, and beliefs regarding different aspects of infant and young child feeding in Eastern and Central Uganda. Methodology: A cross-sectional survey design with mixed methods employing both qualitative and quantitative methods was used for data collection. Results: The study participants included $556 \mathrm{ca}-$ regivers and 572 children. Results indicate that most caregivers (77\%) were knowledgeable about key infant and young child feeding practices such as breastfeeding, complementary feeding and meal frequency. However, culture and economic hardships were a major barrier to the applicability of this knowledge. Nearly all (98\%) children were ever breastfed with $41 \%$ having been initiated on breast milk in the first hour after birth and $68 \%$ of all the children below 6 months exclusively breastfed. Three percent of the children aged 6 23 months were classified as having either Moderate (2\%) or Severe (1\%) Acute malnutrition. The median birth weight was $3.2 \mathrm{Kgs}$ with nine percent of the children classified as underweight at birth. The majority (78\%) of the children consumed foods from at least four food groups however only $44 \%$ consumed heme-rich animal flesh food such as meat, poultry, organ meats and fish, $29 \%$ consumed milk and milk products while only $11 \%$ consumed eggs. The barriers to improved nutritional status and health-seeking behaviour in children from both regions were largely similar. Some of these included cultural practices which prohibit children from eating certain foods and lack of drugs in the health facilities. Lack of male involvement was a key barrier to
\end{abstract}


health-seeking behaviour and the nutritional well-being of children. Males were, however, more knowledgeable about the key childcare practices that are critical to positive outcomes because they listen to radios, have access to social media and usually congregate at bars where this information is disseminated and exchanged. Conclusion: There should be continuous sensitization of mothers on the benefits of breastfeeding with special focus on early initiation and exclusive breastfeeding as well as child feeding practices during illness. To increase protein intake in children 6 - 23 months, interventions aimed at increasing consumption of these vital nutrients such as promotion of nutrition-sensitive agricultural enterprises like rearing of small livestock and chickens should be emphasized. Consumption of these foods is critical, especially during pregnancy and infancy. Finally, male involvement in maternal and child feeding should be encouraged.

\section{Keywords}

Nutritional Status, Knowledge Attitudes and Practices, Breast Feeding, Complementary Feeding, Dietary Diversity, Male Involvement

\section{Introduction}

Chronic undernourishment compromises children's wellbeing and often leads to a high disease burden. The Uganda Bureau of Statistics [1] indicates that prevalence of stunting among children under five years in Eastern and Central Uganda stands at $33 \%$ and $27 \%$ respectively compared to $29 \%$ national stunting average. Similarly, $55 \%$ of the children in the two regions are anemic and only $16 \%$ of children 6 - 23 months have access to the minimum acceptable diet (MAD).

According to Ray, et al. [2], knowledge of caregivers plays an important role in the maintenance of good nutritional status of children. Maternal knowledge, attitudes and practices (KAPs) can have an influence on a child's nutritional pattern and as such, it is critical for mothers to have proper knowledge on dietary practices in the prevention of malnutrition [3].

Although some studies to assess the knowledge, attitudes and practices of caregivers in Uganda have been conducted, these have largely been in controlled conditions such as refugee camps [4] or in children of an older age group i.e. 6 59 months [4] [5]. In addition, prior training in nutritional knowledge and practices was a prerequisite for participation in the aforementioned studies. Such conditions could have a concept of bias in the findings, and it is not surprising that majority of respondents in these studies were quite knowledgeable about nutrition and child feeding practices.

This study, therefore, aimed to assess maternal/caregivers' current knowledge, attitudes, practices and beliefs regarding different aspects of infant and young child feeding (IYCF). Specifically, the study aimed at: 1) Identifying barriers to uptake of promoted IYCF and key health practices; 2) Assessing the nutritional 
status and dietary diversity of children 6 - 23 months; 3) Establishing the prevailing health, diet and contributing social conditions that could have implications on nutrition and health outcomes of children 0 - 23 months; 4) Identifying key actions and key recommendation for improvements in knowledge, attitudes and practices, dietary diversity as well as health-seeking behaviors.

\section{Methods}

A cross-sectional survey design with mixed methods employing both qualitative and quantitative methods of data collection was used. The study was designed to provide representative estimates within the Central and the Eastern regions of Uganda. Specifically, the study was undertaken in Wakiso and Mukono Districts representing Central Region as well as Mayuge and Sironko Districts representing the Eastern Region. The study was conducted between April-June 2018.

\subsection{Study Population}

The study population included all children 0 - 23 months as well as their primary caregivers. Selected residents in the study areas were also identified to participate in focus group discussions (FGDs). All children above 23 months and non-primary caregivers were excluded from the study.

\subsection{Sample Size Determination}

Sample size for caregivers of children 0 - 23 months was determined using the proportion of children under two years who meet the minimum acceptable diet (MAD) in Uganda i.e. 14\% according to the Uganda Bureau of Statistics [1]. Assuming a 5\% non-response rate, sample size was calculated according to the standard formula;

$$
n=\left(D * Z^{2} * p * q\right) / e^{2}
$$

where,

- $n$ is the required sample size, expressed as number of households, for the KEY indicator (see following section on determining the key indicator);

- $p$ is the predicted or anticipated prevalence (coverage rate) for the indicator being estimated;

- $D$ is the design effect assuming it is not a simple random sampling method of respondent selection set at 1.5 ;

- $q$ is $1-p$;

- $e$ is the margin of error set at 0.05 ;

- $Z$ is the level of confidence measure at 95\% (1.96) assuming a normal distribution of the population. This generated a maximum sample size of 291 children per region hence 582 children/care givers for the two regions.

\subsection{Sample Selection}

A four-stage cluster sampling design was used for selection of respondents. First, all districts were stratified into two regions i.e. Eastern and Central regions. In 
each of the regions, two districts were selected using the simple random sampling method. The second stage was to select villages/Enumeration Areas (EAs), also referred to as clusters. In each of the selected districts, a list of all villages including their corresponding number of households was generated from which two sampling frames by region comprising the selected four districts were created. Based on the sample size, 24 households were selected per EA and therefore a total of $26 \mathrm{EAs}$ for the study i.e., $13 \mathrm{EAs}$ per region were selected. The EAs were selected using Systematic Probability Proportionate to Size (SPPS) and based on the Uganda Bureau of Statistics (UBOS) sampling frame of EAs for each district. In the third stage, the 24 households per selected EA were selected using systematic random sampling from a compiled sampling frame. To develop the sampling frame, all households with presence of children $0-23$ months in each given EA were first listed. The fourth and final stage was to identify and interview all caregivers of children $0-23$ months in the selected households. In cases where a household had more than one child aged 0 - 23 months, only one child was considered for this study.

\subsection{Data Collection and Processing}

Quantitative data was collected through use of anthropometry and the household questionnaires [6] while Focus Group Discussions (FGDs) and informant interviews were used for qualitative data. Apart from general household characteristics, the household questionnaire was used to gather information about KAPs on health and nutrition for children. Focus group discussions (FGDs) were used for gathering knowledge, perceptions, opinions, beliefs, attitudes and practices related to food and feeding practices of care takers of children $0-23$ months. Major IYCF, practices that affect outcomes including early initiation, exclusive breast feeding (EBF) for the first six months of a child's life, timely introduction of complementary feeding, diet diversity, intake of animal-source foods, and other food groups were discussed.

Mid-upper arm circumference (MUAC) was used to assess nutritional status of children above 6 months of age while diet adequacy was determined using dietary diversity scores (DDS) for children computed from seven food groups i.e., Grains, roots or tubers, Vitamin A-rich plant foods, Other fruits or vegetables, Meat, poultry, fish, seafood, Eggs, Pulses/legumes/nuts and Milk and milk products [7]. Consumption of four or more food groups was used as a proxy indicator of adequate diet quality.

Data from CAPI devices was centrally captured and exported to the Statistical Package for Social Sciences (SPSS) for checking, cleaning, and analysis. Crosstabulations and regression analysis were majorly used for data analysis.

\subsection{Ethics}

The participants provided informed consent prior to the study. The study was conducted with approval from International Health Sciences University (IHSU) 
Research Ethics Committee (IHSU-REC/0076) and the Uganda National Council for Science and Technology (UNCST).

\section{Results}

The results presented in this paper indicate collective and regional findings from the study.

\subsection{Respondent Characteristics}

Out of the anticipated 582 caregivers and children only 556 caregivers were interviewed and 572 children 0 - 23 months assessed for nutritional status and other health outcomes. Demographic details of the children and their caregivers are indicated in Table 1 below.

Table 1. Demographic characteristics of respondents.

\begin{tabular}{|c|c|c|c|c|c|}
\hline & & & \multicolumn{3}{|c|}{ Region } \\
\hline & & & Overall & Central & Eastern \\
\hline & & & $n(\%)$ & $n(\%)$ & $n(\%)$ \\
\hline & & & $n=572$ & $n=310$ & $n=262$ \\
\hline \multirow{5}{*}{ Children } & \multirow{3}{*}{$\begin{array}{l}\text { Age range of } \\
\text { index child }\end{array}$} & Below 6 months & $145(22)$ & $68(22)$ & $77(29)$ \\
\hline & & $6-11$ months & $158(28)$ & $91(29)$ & $67(26)$ \\
\hline & & $12-23$ months & $269(47)$ & $151(49)$ & $118(45)$ \\
\hline & \multirow{2}{*}{$\begin{array}{l}\text { Gender of } \\
\text { the children }\end{array}$} & Male & $280(49)$ & $156(50)$ & $124(47)$ \\
\hline & & Female & $292(51)$ & $154(50)$ & $138(53)$ \\
\hline \multirow{14}{*}{ Caregivers } & \multirow{6}{*}{$\begin{array}{l}\text { Education } \\
\text { Level }\end{array}$} & & 551 & 300 & 250 \\
\hline & & No formal education & $41(7)$ & $22(7)$ & $19(8)$ \\
\hline & & $\begin{array}{c}\text { Did not } \\
\text { complete primary }\end{array}$ & $155(28)$ & $48(16)$ & $107(43)$ \\
\hline & & Completed Primary & $228(41)$ & $136(45)$ & $92(37)$ \\
\hline & & $\begin{array}{c}\text { Completed } \\
\text { secondary school }\end{array}$ & $118(22)$ & $87(29)$ & $31(12)$ \\
\hline & & Tertiary & $9(2)$ & $7(3)$ & $2(1)$ \\
\hline & \multirow{4}{*}{$\begin{array}{l}\text { Pregnancy } \\
\text { status }\end{array}$} & & 534 & 290 & 244 \\
\hline & & Currently pregnant & $71(13)$ & $29(10)$ & $42(17)$ \\
\hline & & Not pregnant & $455(86)$ & $256(88)$ & $199(82)$ \\
\hline & & Don't know & $8(1)$ & $5(2)$ & $3(1)$ \\
\hline & \multirow{4}{*}{ Marital status } & & 556 & 301 & 255 \\
\hline & & Single & $84(15)$ & $56(18)$ & $28(11)$ \\
\hline & & Married & $466(84)$ & $243(81)$ & $251(87)$ \\
\hline & & No response & $6(1)$ & $2(1)$ & $4(2)$ \\
\hline
\end{tabular}


Overall, majority of the children sampled (47\%) were between 12 - 23 months with gender equally distributed in both regions. All the primary caregivers interviewed were female with more than $40 \%$ aged between 18 - 34 years. Likewise, $41 \%$ of the care givers had completed primary school and over $80 \%$ were married.

\subsection{Children's Health and Nutritional Status}

Over $97 \%$ of all the children were ever breastfed with $41 \%$ having been initiated on breast milk in the first hour after birth while $68 \%$ of all the children below 6 months were exclusively breastfed. Vitamin A supplementation was indicated for $63 \%$ of the children. It was however concerning to note that although the Ugandan health authorities do not advocate for Vit A supplementation before 6 months of age, $36 \%$ of all children less than 6 months had been supplemented with Vitamin A.

A diarrhoea episode within the preceding seven days before data collection was reported in $41 \%$ of the children with $10 \%$ reported to have had bloody stools. Diarrhoea episodes were mostly seen in 6-11 months old children probably because such children have just started crawling and are prone to picking and eating anything they come across. Children below 6 months were more likely to suffer from bloody diarrhoea (13\%) compared to $9 \%$ of the older children. Majority of the caretakers (61\%) sought treatment for diarrhoea from private and government health facilities or pharmacies with a few seeking help from a community health provider. The remaining 39\% let the diarrheal episodes run course without treatment. Oral rehydration solutions were used by over $95 \%$ of all those who sought treatment for diarrhoea. Only $10 \%$ of the children who suffered from diarrhoea received more fluids and food than usual. Details are indicated in Table 2.

\subsection{Children's Individual Dietary Diversity Scores (DDS)}

The dietary diversity is used as a proxy measure of the nutritional quality of an individual's diet as well as micronutrient adequacy [8]. For children, the dietary diversity scores (DDS) from seven food groups i.e. Grains, roots or tubers, Vitamin A-rich plant foods, Other fruits or vegetables, Meat/poultry/fish/seafood, Eggs, Pulses/legumes/nuts and Milk and milk products were computed and a cut off of four food groups was used as a proxy indicator of diet quality. Results (Table 3 ) revealed that majority (78\%) of the children consumed foods from four or more groups in the 24 hours prior to data collection. Children in the 12 23 months age category consumed more diverse meals (83\%) than those in the 6 - 11 months category (70\%).

Furthermore, consumption of foods from each of the various food groups by the 6 - 23 months old children was also assessed. As shown in Table 4, 94\% of the children surveyed consumed starchy staples. Consumption of Vitamin A-rich plant foods, eggs, milk and heme-rich (meat, poultry, organ meats, fish 
Table 2. Health indicators of children 0 - 23 months.

\begin{tabular}{|c|c|c|c|c|c|c|c|}
\hline & & \multicolumn{3}{|c|}{ Region } & \multicolumn{3}{|c|}{ Age group (months) } \\
\hline & & Overall & Central & Eastern & Below 6 & $\begin{array}{c}6-11 \\
\text { months }\end{array}$ & $\begin{array}{l}12-23 \\
\text { months }\end{array}$ \\
\hline & & $n(\%)$ & $n(\%)$ & $n(\%)$ & $n(\%)$ & $n(\%)$ & $n(\%)$ \\
\hline & $N=$ & 572 & 310 & 262 & 145 & 158 & 269 \\
\hline \multirow{4}{*}{ MUAC results } & $N=$ & 427 & 242 & 185 & NA & 158 & 269 \\
\hline & SAM & $1(0.3)$ & $1(0.4)$ & $0(0)$ & $N A$ & $0(0)$ & $1(0.4)$ \\
\hline & MAM & $10(2.3)$ & $3(1.3)$ & $7(4)$ & $N A$ & $5(3)$ & $5(1.9)$ \\
\hline & Normal & $416(97.4)$ & $238(98.3)$ & $178(96)$ & $N A$ & $153(97)$ & $263(97.7)$ \\
\hline \multirow{3}{*}{$\begin{array}{l}\text { Ever been } \\
\text { breastfed }\end{array}$} & Yes & $553(97)$ & $297(96)$ & $256(98)$ & $142(98)$ & $152(96)$ & $259(96)$ \\
\hline & No & $18(3)$ & $13(4)$ & $6(2)$ & $2(1)$ & $6(4)$ & $10(4)$ \\
\hline & IDK & $0(0)$ & $0(0)$ & $0(0)$ & $1(1)$ & $0(0)$ & $0(0)$ \\
\hline \multirow{3}{*}{$\begin{array}{l}\text { Initiation of } \\
\text { breastfeeding }\end{array}$} & First hour & $225(41)$ & $137(46)$ & $88(34)$ & $55(39)$ & $62(41)$ & $108(41)$ \\
\hline & $\begin{array}{c}\text { After one } \\
\text { hour, in a day }\end{array}$ & $317(57)$ & $152(51)$ & $165(64)$ & $85(60)$ & $88(58)$ & $144(56)$ \\
\hline & After one day & $11(2)$ & $8(3)$ & $3(2)$ & $2(1)$ & $2(1)$ & $7(3)$ \\
\hline \multirow{2}{*}{$\begin{array}{l}\text { Feeding on } \\
\text { other liquids }\end{array}$} & Yes & $178(31)$ & $120(39)$ & $58(22)$ & $47(32)$ & $51(32)$ & $80(30)$ \\
\hline & No & $394(69)$ & $190(61)$ & $204(78)$ & $98(68)$ & $107(68)$ & $189(70)$ \\
\hline \multirow{2}{*}{ Diarrhoea } & Yes & $233(41)$ & $131(43)$ & $102(39)$ & $40(28)$ & $83(53)$ & $110(41)$ \\
\hline & No & 338 (59) & $178(57)$ & $160(61)$ & $105(72)$ & 75 (47) & $158(59)$ \\
\hline \multirow{3}{*}{ Bloody stool } & Yes & $23(10)$ & $10(8)$ & $13(13)$ & $5(13)$ & $8(10)$ & $10(9)$ \\
\hline & No & 209 (90) & $120(92)$ & $89(87)$ & $34(85)$ & $75(90)$ & $100(91)$ \\
\hline & IDK & $0(0)$ & $0(0)$ & $0(0)$ & $1(3)$ & $0(0)$ & $0(0)$ \\
\hline \multirow{2}{*}{ RTI } & Yes & $424(74)$ & $236(76)$ & $188(72)$ & $102(70)$ & $127(80)$ & $195(72)$ \\
\hline & No & $148(26)$ & $74(24)$ & $74(28)$ & $43(30)$ & $31(20)$ & $74(28)$ \\
\hline \multirow{2}{*}{ Fever } & Yes & 269 (47) & $138(45)$ & $131(50)$ & $56(39)$ & $86(54)$ & $127(47)$ \\
\hline & No & 302 (53) & $171(55)$ & $131(50)$ & $88(61)$ & $72(46)$ & $142(53)$ \\
\hline \multirow{3}{*}{$\begin{array}{c}\text { Vitamin A } \\
\text { supplementation }\end{array}$} & Yes & $360(63)$ & $182(59)$ & $178(68)$ & $52(36)$ & $125(79)$ & $183(68)$ \\
\hline & No & 207 (36) & $124(40)$ & $83(32)$ & $92(63)$ & $32(20)$ & $83(31)$ \\
\hline & IDK & $5(1)$ & $4(1)$ & $0(0)$ & $1(1)$ & $1(1)$ & $3(1)$ \\
\hline
\end{tabular}

IDK = I don't Know.

Table 3. Dietary diversity scores of the sampled children 6 - 23 months.

\begin{tabular}{cccccc}
\hline & \multicolumn{3}{c}{ Region } & \multicolumn{2}{c}{ Age category (months) } \\
\cline { 2 - 6 } & $\begin{array}{c}\text { Overall, } \\
n(\%)\end{array}$ & $\begin{array}{c}\text { Central } \\
n(\%)\end{array}$ & $\begin{array}{c}\text { Eastern } \\
n(\%)\end{array}$ & $\begin{array}{c}6-11 \\
n(\%)\end{array}$ & $\begin{array}{c}12-23 \\
n(\%)\end{array}$ \\
\hline$N=$ & 427 & 242 & 185 & 158 & 269 \\
\% of children with DDS $<4$ & $94(22)$ & $56(23)$ & $39(21)$ & $47(30)$ & $46(17)$ \\
\% of children with DDS $>4$ & $333(78)$ & $186(77)$ & $146(79)$ & $111(70)$ & $223(83)$ \\
\hline
\end{tabular}


Table 4. Consumption of various food groups by children 6 - 23 months.

\begin{tabular}{cccccc}
\hline & \multicolumn{2}{c}{ Region } & Age category (months) \\
\cline { 2 - 6 } & $\begin{array}{c}\text { Overall } \\
\boldsymbol{n}(\%)\end{array}$ & $\begin{array}{c}\text { Central } \\
\boldsymbol{n}(\%)\end{array}$ & $\begin{array}{c}\text { Eastern } \\
\boldsymbol{n}(\%)\end{array}$ & $\begin{array}{c}6-11 \\
\boldsymbol{n}(\%)\end{array}$ & $\begin{array}{c}12-23 \\
\boldsymbol{n}(\%)\end{array}$ \\
\hline$N=$ & $\mathbf{4 2 7}$ & $\mathbf{2 4 2}$ & $\mathbf{1 8 5}$ & $\mathbf{1 5 8}$ & $\mathbf{2 6 9}$ \\
Starchy staples & $401(94)$ & $223(92)$ & $178(96)$ & $147(93)$ & $261(97)$ \\
Vitamin A rich foods & $290(68)$ & $155(64)$ & $133(72)$ & $100(63)$ & $204(76)$ \\
Other fruits and vegetables & $376(88)$ & $223(92)$ & $154(83)$ & $138(87)$ & $253(94)$ \\
Legumes and nuts & $329(77)$ & $177(73)$ & $154(83)$ & $117(74)$ & $226(84)$ \\
Milk and milk products & $124(29)$ & $92(38)$ & $33(18)$ & $40(25)$ & $83(31)$ \\
Meat and fish & $188(44)$ & $109(45)$ & $80(43)$ & $65(41)$ & $129(48)$ \\
Eggs & $47(11)$ & $32(13)$ & $15(8)$ & $11(7)$ & $35(13)$ \\
\hline
\end{tabular}

and seafood) foods was used to assess children's micronutrient intake in this study. Results showed that across both regions, $68 \%$ of children were fed on vitamin A rich foods, $29 \%$ were fed on milk and milk products and only $11 \%$ were fed on eggs. Meat and fish consumption were consumed by only $44 \%$ of the children.

\section{Factors Associated with Individual Dietary Diversity for Children}

Regression analysis for the factors that were associated with the dietary diversity children in the selected households was run and is summarized in Table 5. Age of the child, vitamin A supplementation and breastfeeding were significantly ( $\mathrm{p}$ $<0.05)$ correlated with the dietary diversity scores of the children in both regions. Older children (12 - 23 months), those who had ever breastfed and vitamin A supplemented children were more likely to have a higher diet diversity score. This can be explained by the fact that as children grow older, breast feeding is less likely to continue, and children will be introduced to family foods. In addition, they become less reliant on their caretakers for food and can sometimes move to other households and consume foods not present in their households.

In addition, whether the child had ever been breastfed was significantly related to their dietary diversity possibly because this may contribute to current health status, and in turn contribute to appetite. A relationship was also seen between Vitamin A supplementation and dietary diversity scores of the children. Again, this can also be related to improved health status and hence improved appetite. No relationship was however seen between maternal education level, marital status, or location of residence regarding nutrition and dietary diversity scores.

\subsection{Maternal Knowledge on Infant and Young Child Feeding}

Maternal knowledge regarding IYCF was assessed by use of key indicators as shown in Table 6 below. 
Table 5. Linear regression of dietary diversity scores for children 6 - 23 months and selected variables.

\begin{tabular}{ccc}
\hline & \multicolumn{2}{c}{ General } \\
\hline Variable & Coef (B) & Sig \\
\hline Constant & 3.048 & \\
Age (Months) & 0.045 & $0.000^{*}$ \\
Breastfed & -0.251 & $0.040^{*}$ \\
Diarrhoea & -0.040 & 0.702 \\
Vitamin A Supplement & 0.417 & $0.000^{*}$ \\
Rural & 0.119 & 0.431 \\
Married & 0.158 & 0.284 \\
Completed Primary & 0.197 & 0.310 \\
Completed Ordinary level & 0.138 & 0.522 \\
Completed A level & -0.092 & 0.808 \\
Completed University & 0.865 & 0.174 \\
Completed other Tertiary & 1.259 & 0.102 \\
Did not complete Primary & 0.204 & 0.312 \\
\hline
\end{tabular}

Note: Durbin-Watson $=2.029$, R-square $=0.114$, VIF ranges from 1.012 to $3.442, \mathrm{~F}(12,403)=4.309, \mathrm{p}<$ 0.001. Dependent variable: Number of Food groups eaten.

Table 6. Care-giver knowledge on infant and young child feeding/Nutrition.

\begin{tabular}{|c|c|c|c|c|}
\hline & & \multirow{4}{*}{$\begin{array}{c}\text { Total } \\
N=556\end{array}$} & \multicolumn{2}{|c|}{ Region } \\
\hline & & & Central & Eastern \\
\hline & & & $N=301$ & $N=255$ \\
\hline & & & $n(\%)$ & $n(\%)$ \\
\hline \multirow{2}{*}{ Complementary feeding age } & Know & $427(77)$ & $240(80)$ & $187(73)$ \\
\hline & Don't know & $129(23)$ & $61(20)$ & $68(27)$ \\
\hline \multirow{2}{*}{ Ingredients for baby food } & Know & $522(94)$ & $282(94)$ & $240(96)$ \\
\hline & Don't know & $34(6)$ & $19(6)$ & $15(4)$ \\
\hline \multirow{2}{*}{ Encouraging consumption } & Know & $409(74)$ & $233(77)$ & $176(69)$ \\
\hline & Don't know & $147(26)$ & $68(23)$ & $79(31)$ \\
\hline \multirow{2}{*}{ Food for strength/intelligence } & Know & $541(97)$ & $292(97)$ & $249(98)$ \\
\hline & Don't know & $15(3)$ & $9(3)$ & $6(2)$ \\
\hline \multirow{2}{*}{ Reasons for malnutrition } & Know & $517(93)$ & $284(94)$ & $233(91)$ \\
\hline & Don't know & $39(7)$ & $17(6)$ & $22(9)$ \\
\hline \multirow{2}{*}{ Childcare practices } & Know & $535(96)$ & $293(97)$ & $242(95)$ \\
\hline & Don't know & $21(4)$ & $8(3)$ & $13(5)$ \\
\hline
\end{tabular}

As shown, many caregivers had knowledge on various aspects such as right age to start complementary feeding (77\%) and ingredients that can be added to 
improve the nutritional content of a baby's food (94\%). Among the aspects surveyed, however, a relatively high percentage of caregivers (26\%) were not knowledgeable about how children could be encouraged to consume more food. Some of the claimed that forcing a child to eat would make them consume more food while others claimed that sweetening the food would boost a child's appetite and therefore make them consume more food. These practices are both not encouraged as the former could make a child associate food with pain and discomfort (making them eat less) while the latter is associated with health risks such tooth decay and obesity among others.

\subsection{Attitudes and Barriers to IYCF Practices and Health}

Focus Group Discussions (FGDs) and Key informant interviews were used to gather knowledge, views, perceptions, opinions, beliefs, attitudes and practices related to health seeking behavior as well as food and feeding practices of children 0 - 23 months.

Overall, the respondents were knowledgeable about key IYCF practices such breastfeeding, timely introduction of complimentary foods. They were aware that children should be given variety of nutritious foods prepared in a hygienic environment. There were, however, some notable practices and attitudes that could affect nutritional status of infants and pregnant woman hence compromising the health status of the unborn child. Examples of such beliefs and practices included;

1) "Children should not eat meat before they have started talking". Implying that if a child delays to talk they may be deprived of nutritious animal foods hence predisposing them to malnutrition

2) When children eat meat, they will become greedy adults.

3) If a pregnant woman eats fish, she will produce a baby with scaly skin.

\subsubsection{Male Involvement in Food and Feeding}

It was noted that men were not involved in decision making regarding food and nutrition in the homesteads, yet men were very knowledgeable about key IYCF practices. This was largely to the fact that they often listen to radios and watch TV at social gatherings like bars where key IYCF messages are more likely to be broad cast. Majority of the male household heads believed that food and feeding in the home is the responsibility of the women. This lack of interest in what the children feed on might lead to malnutrition especially if the mothers are not economically empowered or not knowledgeable about key IYCF practices.

The fact that men believed that food and feeding at home was a responsibility of the women was largely due to ignorance and some were genuinely surprised that their support was crucial to the well-being of their families as evidenced by responses like the one below:

"You mean a man can also prepare food in a home? No! When my wife is pregnant, I send her to her relatives, and she will return after the baby is born. She has to go with all her children because I can't cook for them." 
The above statement was made by one of the respondents during an FGD for men within the community. On hearing that other men in the group help their women with home chores, he indicated willingness to change and start helping in the home.

\subsubsection{Health Seeking Behavior}

Poor economic status was one of the major barriers to health seeking behavior of the caregivers. From the discussions, children were more likely to be taken for regular medical checkups during the first year of life where immunization is a priority and usually a free service provided by the government. After one year, children were only likely to be taken for routine medical checkups, deworming and supplementation or treatment only if the caretaker failed to manage health complications at home or if there was an on-going medical outreach offering free services.

"When my child has malaria, I first give mululuza (herbal remedy), then Panadol. If it persists, I get coartem from the clinic and if that also fails, I go to hospital." This was one caretaker's response to management of a child with malaria and majority of the group members agreed to do the same in similar situations.

\section{Discussion and Recommendations}

\subsection{Infant, Young Child Feeding and Other Health Seeking Behaviour}

The key aspects of IYCF are discussed in the sections below.

\subsubsection{Breastfeeding}

Compared to the Ugandan national average of $66 \%$ for both early initiation and exclusive breastfeeding, results from this study show a low prevalence of early initiation (41\%) and exclusive breastfeeding (68\%) respectively. Early initiation of breastfeeding triggers the release of hormones which help the mother's uterus contract and prevent hemorrhage [9]. In addition, according to the World Health Organization [10], and provides colostrum which has protective benefits for the baby and also encourages future milk production. Therefore, the low prevalence of early initiation is a disadvantage to the children and intervetions aimed at increasing the number of mothers who practice early initiation should be promoted.

Introduction of foods other than breast milk during the first six months predisposes children to repeated infection and hence growth retardation. One of the factors that may affect exclusive breastfeeding is the fact that women do not get as much care and attention from their partners. "Men don't usually care about us after delivery. It is only during pregnancy that a man will buy nutritious foods like milk and eggs but after birth you have to care for yourself and the baby", was one care-taker's statement during an FGD in Wakiso district. Such a statement indicates that due to the fact that women have to fend for themselves after 
pregnancy, they may not have sufficient means to ensure a healthy diet which in turn affects breast milk production, hence breastfeeding. Male involvement to support breastfeeding is therefore crucial in addition to support during pregnancy.

\subsubsection{Complimentary Feeding}

Timely and appropriate complimentary feeding and continued breastfeeding is important for the proper growth of children. It is recommended that children be given other foods apart from breast milk from 6 months of age onwards to meet additional energy and other nutrient requirements [11]. Majority (77\%) of the respondents were knowledgeable about when to start complimentary feeding and identified poor unbalanced diets and insufficient food quantity as some of the major causes of childhood malnutrition. It was however noted that only half of the respondents knew that animal source foods apart from silver fish (mukene) were important in the proper nutrition of the growing child. There is therefore need for more education on importance of animal source foods in the diet of a growing child. Interventions such as small livestock farming (chicken, rabbits etc) could be encouraged for home consumption.

\subsubsection{Individual Dietary Diversity-Children}

Results from the individual dietary diversity scores of the children show that on average, many children are consuming food from at least four food groups in both central and the eastern regions. This implies that the children are consuming food from the minimum number of food groups required to contribute to improved nutrition outcomes. According to the Uganda Demographic Health Survey [12], the minimum acceptable diet indicator is used to assess the proportion of children age 6 - 23 months who meet minimum standards with respect to three IYCF criteria i.e. dietary diversity, breastfeeding and meal frequency. Although over $75 \%$ of children the children surveyed had a dietary diversity score of four food groups; hence meeting one of the IYCF criteria for a minimum acceptable diet, efforts however need to be made to increase the number of food groups from which food is consumed through promotion of nutrition sensitive enterprises like chicken and small livestock rearing.

Study results showed a generally low consumption of animal source protein such as meat, milk and especially eggs in both regions among children. Animal source proteins have a high biological value and contain essential nutrients that are essential for the growth and development of children especially in the first 1000 days of life. Interventions aimed at increasing consumption of these vital nutrients such as promotion of nutrition sensitive agricultural enterprises like rearing of small livestock and chickens should be emphasized to improve the consumption of these foods which are critical during pregnancy and infancy. In addition, promotion of cheaper high biological value protein sources like silver fish and insects might have positive implications on maternal and infant dietary diversity. 


\subsubsection{Diarrhea}

Although World Health Organization [13] recommends that fluids and feeds be increased during a diarrheal episode, only $10 \%$ of the children who suffered from diarrhoea in this survey were reported to have received more fluids than usual. The rest either received the same amount of fluid or much less than usual. Such practices can exacerbate the negative effects of childhood diarrhoea including mortality. It was also noted that oral rehydration solutions were majorly used for treatment of diarrhoea. Majority of the respondents ( $>50 \%)$ were more likely to seek treatment from a community health worker before going to a health facility for further assistance in worse situations. There is therefore need for more training and empowerment of community health workers to manage common childhood infections since they are the first step of interface. The community workers should also be provided with affordable rehydration solutions for community use.

\subsection{Social Barriers to Improved Child Nutrition}

Male involvement was identified as one of the key enablers/barriers to good child feeding practices hence nutritional status. It was however noted that majority of the men were ignorant about the importance of their support and when educated were willing to change their attitude towards child feeding.

"I will provide anything that is required for feeding children as duty and a must so that my children can have strong immunity" stated one male respondent from one discussion.

Such indicates that men are willing to provide support for their dependents (women/children) to improve their health and wellbeing. More sensitization is however needed on the benefits and ways in which they can support their spouses and children.

\subsection{Summary of Key Recommendations}

Considering the findings of this study, a summary of key recommendations to local government and others service providers for purposes of programming and service delivery is given.

\subsubsection{Infant and Young Child Feeding Practices}

There should continuous sensitization of mothers on the benefits of breastfeeding with special focus on early initiation and exclusive breastfeeding.

Male household heads should be encouraged to provide support to their partners during pregnancy and lactation. This support can be in form of providing nutritious foods, assisting with home chores, emotional support etc.

Nutrition education sessions on IYCF should place emphasis on important complementary feeding practices such as hygienic food preparation, dietary diversity and continued breast feeding after 6 months.

\subsubsection{Child Dietary Diversity}

Key cultural beliefs and practices that may have implications on nutritional 
well-being of children should be addressed through channels such as community, religious and political leaders as well as media such radio talk shows, skits etc.

Nutrition sensitive agricultural enterprises such as small livestock \& poultry rearing should be encouraged and supported to improve access to and consumption of animal source foods to improve dietary diversity.

Access to affordable agricultural inputs such as improved and bio fortified planting materials should be improved to increase production as well nutritional value of plant source foods. Such materials may include iron-rich beans, Orange Fleshed Sweet potato vines, Vitamin A rich cassava cutlets etc.

Programs that promote and encourage consumption of locally available micronutrient rich fruits and Vegetables should be designed and included in the project activities.

\subsubsection{Health Seeking Behavior for Children}

Community health workers should be trained on the management of common childhood illnesses such as diarrhea so that they can ably provide affordable assistance in the treatment and management of such conditions. This could contribute to the reduction of self-medication and care.

Affordable quality health commodities including ORS, malaria and deworming tablets should be availed to households through community health workers and local drug shops to ease access and therefore treatment of common childhood illnesses.

\subsection{Conclusion}

In conclusion, there should be continuous sensitization of mothers on the benefits of breastfeeding through various Social Behavior Change and Communication (SBCC) activities. Emphasis of the SBCC should be placed on early initiation and exclusive breastfeeding as well as child feeding practices during illness. In order to increase protein intake in children $6-23$ months, interventions aimed at increasing consumption of these vital nutrients such as promotion of nutrition-sensitive agricultural enterprises like rearing of small livestock and chickens should be emphasized in order to improve the consumption of these foods which are critical during pregnancy and infancy. Finally, male involvement in maternal and child feeding should be encouraged.

\subsection{Limitations}

The major limitation faced during field work was the harsh weather conditions and terrain i.e. heavy rains and impassable roads that sometimes made it impossible to work according to schedule. In addition, many mothers/caretakers did not have children's health cards, making it difficult to verify the information from mothers' recall.

\section{Funding}

The study was conducted using funds from Living Goods, Uganda 


\section{Authors' Contributions}

JKA, JN, JK, GWS and PK designed, executed the study, and wrote the manuscript, LN contributed to writing of manuscript.

\section{Conflicts of Interest}

The authors declared no potential conflicts of interest with respect to the research, authorship, and/or publication of this article.

\section{References}

[1] Uganda Bureau of Statistics (2016) Uganda Demographic and Health Survey. https://www.ubos.org/

[2] Ray, S., Mishra, R., Biswa, R., Kumar R.R., Halden, A. \& Chattrjee, T. (1999) Nutritional Status of Pavement Dweller Children of Calcutta City. Indian Journal of Public Health, 43, 49-54.

[3] Michael, E. and Lakshimi, P. (2016) Knowledge, Attitude, and Practice (KAP) Survey on Dietary Practices in Prevention of Malnutrition among Mothers of Under-Five Children. Emergency Nutrition Network (ENN), 2, 19-24.

[4] Nassanga, P., Okello-Uma, I. and Ongeng, D. (2018) The Status of Nutritional Knowledge, Attitude and Practices Associated with Complementary Feeding in a PostConflict Development Phase Setting: The Case of Acholi Sub-Region of Uganda. Food Science \& Nutrition, 6, 2374-2385. https://doi.org/10.1002/fsn3.829

[5] Nabugoomu, J., Namutebi, A., Kaaya, A. and Nasinyama, G. (2015) Nutrition Education Influences Child Feeding Knowledge, Attitudes and Practices of Caregivers in Uganda. American Journal of Health Research, 3, 82-90.

https://doi.org/10.11648/j.ajhr.20150302.15

[6] United Nations Children's Fund (UNICEF) (2017) MICs6 TOOLS Guidelines and Templates Facilitate Planning and Design of Surveys and Help Avoid Pitfalls in Implementation. https://mics.unicef.org/tools

[7] Food and Agricultural Organization (2010) Guidelines for Measuring Household and Individual Dietary Diversity. Food and Agricultural Organization, Rome, Italy.

[8] Food and Agricultural Organization \& Food and Nutrition Technical Assistance (2016) Minimum Dietary Diversity for Women-A Guide for Measurement. Food and Agricultural Organization, Rome, Italy.

[9] Saxton, A., Fahy, K., Rolfe, M., Skinner, V. and Hastie, C. (2015) Does Skin-to-Skin Contact and Breast Feeding at Birth Affect the Rate of Primary Postpartum Haemorrhage: Results of a Cohort Study. Midwifery, 31, 1110-1117. https://doi.org/10.1016/j.midw.2015.07.008

[10] World Health Organization (2018) Implementation Guidance: Protecting, Promoting and Supporting Breastfeeding in Facilities Providing Maternity and Newborn Services-the Revised Baby-Friendly Hospital Initiative. World Health Organization, Geneva.

[11] World Health Organization (2009) Infant and Young Child Feeding: Model Chapter for Textbooks for Medical Students and Allied Health Professionals. World Health Organization, Geneva.

[12] Uganda Bureau of Statistics (2011) Uganda Demographic and Health Survey. https://www.ubos.org

[13] World Health Organization (2014) Integrated Management of Childhood Illnesses. World Health Organization, Geneva. 